\title{
Complementary use of Optical Coherence Tomography (OCT) and Reflection FTIR spectroscopy for in-situ non-invasive monitoring of varnish removal from easel paintings
}

Magdalena Iwanicka ${ }^{(a)}$, Patrizia Moretti ${ }^{(b, c)}$, Saskia van Oudheusden ${ }^{(d)}$, Marcin Sylwestrzak ${ }^{(e)}$, Laura Cartechini $^{(b)}$, Klaas Jan van den Berg ${ }^{(\mathrm{d})}$, Piotr Targowski ${ }^{(\mathrm{e})}$, Costanza Miliani $^{\left({ }^{(b)}\right.}$

(a) Institute for the Study, Conservation and Restoration of Cultural Heritage, Faculty of Fine Arts, Nicolaus Copernicus University, ul. Sienkiewicza 30/32, 87-100 Torun, Poland; magiwani@gmail.com (corresponding author)

(b) Istituto di Scienze e Tecnologie Molecolari (CNR-ISTM), Via Elce di Sotto, 8, 06123 Perugia, Italy

(c) Dipartimento di Chimica, Biologia, e Biotecnologie, Università di Perugia, Via Elce di Sotto, 8, 06123 Perugia, Italy

(d) Cultural Heritage Agency of the Netherlands (RCE), Hobbemastraat 22, 1071 ZC Amsterdam, The Netherlands

(e) Institute of Physics, Faculty of Physics, Astronomy and Informatics, Nicolaus Copernicus University, ul. Grudziądzka 5, 87-100 Torun, Poland

\section{Higlights:}

- Reflection FTIR spectroscopy and OCT, when used together, enhance insight into the details of cleaning of easel paintings

- FTIR complements OCT structural images by providing crucial information on the chemical composition of superficial layers

- OCT complements the FTIR spectral data with information on the thicknesses of layers, both removed and left

- This integrated approach increases the safety of the cleaning treatment.

\begin{abstract}
Although the solvent removal of unwanted layers (e.g. aged varnishes, overpaints, oxalate patinas, dirt from easel paintings is one of the most frequently performed restoration treatments it is questioned regarding its controllability and safety to the artwork. There is thus a need for developing suited diagnostic methodologies able to inform restorers on the chemical, optical and morphological effects of cleaning. To this aim, we have explored the possibility of complementary use of Optical Coherent Tomography (OCT) and reflection FTIR. On the one hand, the OCT technique provides cross-sectional images with varnish layers visible and thus permits for measurement of their thicknesses. Combining many cross-sections into 3D data provides insight into the varnish thickness distribution over a given area of the paintings. On the other hand, reflection FTIR allows for a chemical characterization of the surface compounds revealing the nature of the varnish and monitoring its removal. Artificially aged model samples and two historical paintings were investigated at different steps of solvent cleaning tests and the results of the two techniques compared highlighting the benefits of their combined exploitation.
\end{abstract}

\section{Keywords}

optical coherence tomography, reflection FTIR spectroscopy, assessment of cleaning treatment, varnish removal, easel painting, restoration monitoring 


\section{Introduction}

Yellowed or otherwise deteriorated varnishes may significantly impair visual perception of an easel painting. This also holds for surface dirt, crusts, overpaints and some other substances introduced during past restoration treatments. Removal of such visually obscuring, generally non-original materials from paintings' surfaces using solvents, usually referred to 'solvent cleaning', is one of the most common conservation procedures in paintings conservation. It is also considered to be one of the most potentially hazardous to the historical objects, especially when fragile or solvent sensitive original structures are present under the undesired layers [1, 2]. Much systematic research has been done to improve risk assessment and practical application of solvent cleaning methodologies [3]. However, the development of additional analytical instruments that improve the evaluation of varnish removal is still highly encouraged amongst conservators. Within the joint research activities of the IPERION CH project [4] a specific task is dedicated to the development of non-invasive analytical methodologies, which, by combining different techniques currently available through the European mobile infrastructure $\operatorname{MOLAB}[5,6]$, would offer to conservators-restorers access to advanced chemical and physical information on the effect of solvent cleaning. As a result of this research, here an approach based on the integration of the stratigraphic information obtained from optical coherence tomography (OCT) with the chemical characterization of superficial layers accessible through reflection FTIR spectroscopy is presented and discussed.

The potential of each technique for a non-invasive in-situ monitoring of cleaning of paintings has been already proved by feasibility studies performed during the restoration of some paintings. Within the activity of MOLAB, reflection FTIR spectroscopy has been used to assess the removal of compounds such as oxalates $[7,8]$, non-ionic surfactants [9] and natural varnishes $[7,10]$, proving to have adequate sensitivity and specificity.

Optical coherence tomography (OCT) [11-14] has been used previously for the assessment of removal of varnishes or overpaints from historical easel paintings by means of solvent cleaning. The evaluation of the removal of layers was based on the analysis of OCT cross-sections exclusively $[15,16]$ in order to aid the conservators-restorers to choose optimal solvent composition and application procedure. The technique was also used for the real-time monitoring of laser cleaning of painted and varnished samples [17, 18]. Several optical non-invasive techniques (colorimetry, conoscopic profilometry, OCT, and reflection FTIR) were explored by Striova et al. for the monitoring of cleaning of mural paintings of both chemical and laser thinning of shellac varnish [19] or calcium oxalate patina[20].

Here a systematic evaluation of limits and potential of reflection FTIR and high resolution OCT used in a complementary approach for monitoring of the selective removal of natural and/or synthetic varnishes from oil-based easel paintings has been carried out. Correlations between the characterization of the chemical surface composition by FTIR with the OCT stratigraphic information (both 2D and 3D) were critically investigated working on multi-layered paint models. The integrated approach was then tested for cleaning experiments on two historical oil easel paintings.

\section{Materials and methods}

\subsection{Model samples and easel paintings examined}

For the IPERION CH project a broad set of mock-ups was prepared. They were made on different supports and with different paints, all varnished with dammar varnish, aged and later covered with four types of other varnishes. The results for the assessment of cleaning tests on the following four model samples (see Table 1 and Fig. 1a) have been chosen to be discussed in this paper. 
Table 1: list and description of the paint models and cleaning treatments

\begin{tabular}{|c|c|c|c|}
\hline \multicolumn{2}{|r|}{ Paint models } & \multicolumn{2}{|c|}{ Cleaning } \\
\hline Name & Layer structure and composition (from bottom) & Solvents & Procedure \\
\hline Sample $D+A$ & $\begin{array}{l}\text { a: canvas } \\
\text { b: priming } \\
\text { c: oil paint (titanium white, Rembrandt, Talens)* applied by } \\
\text { brushing } \\
\text { d: natural surface dirt* } \\
\text { e: one layer of dammar applied by brushing** } \\
\text { f: one layer of acrylic varnish (Maimeri 58667) applied by } \\
\text { brushing }\end{array}$ & $\begin{array}{l}\text { white spirit } \\
+ \text { xylene } \\
\text { (1:1 parts } \\
\text { by volume) }\end{array}$ & $\begin{array}{l}\text { Solvent mixture } \\
\text { applied by } \\
\text { swabbing in } 3 \\
\text { steps } \\
\text { (3 rolls per step) }\end{array}$ \\
\hline Sample D+M & $\begin{array}{l}\text { a: canvas } \\
\text { b: priming } \\
\text { c: oil paint (titanium white, Rembrandt, Talens)* applied by } \\
\text { brushing } \\
\text { d: natural surface dirt* } \\
\text { e: one layer of dammar applied by brushing** } \\
\text { f: } 1 \text { layer of microcrystalline wax (Zecchi, dissolved in ligroin) } \\
\text { applied by brushing }\end{array}$ & white spirit & $\begin{array}{l}\text { Solvent applied } \\
\text { by swabbing in } \\
2 \text { steps } \\
\text { ( } 3 \text { rolls per step) }\end{array}$ \\
\hline $\begin{array}{l}\text { Sample } \\
D+A+L\end{array}$ & $\begin{array}{l}\text { a: cardboard } \\
\text { b: priming } \\
\text { c: acrylic paint (ochre, Rembrandt, Talens) applied by } \\
\text { brushing* } \\
\text { d: three layers of matt dammar (Talens 082)† applied by } \\
\text { brushing* } \\
\text { e: one layer of matt acrylic varnish (Talens 115)† applied by } \\
\text { spraying* } \\
\text { f: one layer of urea- aldehyde varnish Laropal A } 81 \text { (CTS) } \\
\text { applied by brushing }\end{array}$ & $\begin{array}{l}\text { white spirit } \\
+ \text { xylene } \\
\text { (1:1 pbv) }\end{array}$ & $\begin{array}{l}\text { Solvent mixture } \\
\text { applied by } \\
\text { swabbing in } 2 \\
\text { steps } \\
\text { (3 rolls per step) }\end{array}$ \\
\hline Sample D+B & $\begin{array}{l}\text { a: cardboard } \\
\text { b: priming } \\
\text { c: acrylic paint (burnt umber, Rembrandt, Talens) applied by } \\
\text { brushing* } \\
\text { d: one layer of matt dammar (Talens 082)† applied by } \\
\text { brushing* } \\
\text { e: one layer of artificial dirt (pure carbon soot, Kremer } \\
\text { Pigmente) } \\
\text { f: one layer of beeswax (dissolved in ligroin) applied by } \\
\text { brushing }\end{array}$ & white spirit & $\begin{array}{l}\text { Solvent applied } \\
\text { by swabbing in } \\
2 \text { steps } \\
\text { ( } 3 \text { rolls per step) }\end{array}$ \\
\hline
\end{tabular}

letters a-e correspond to markers of layers in Fig. 1a

* naturally aged indoor for 10 years

**applied in 2015 and artificially aged for 336 hours in dark chamber, 50 ${ }^{\circ} \mathrm{C}, 30-80 \% \mathrm{RH}$ (Heraeus Votsch Vc 0020)

tvarnish formulation with silica as matting agent. 


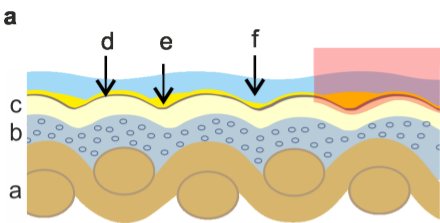

sample $\mathrm{D}+\mathrm{A}$

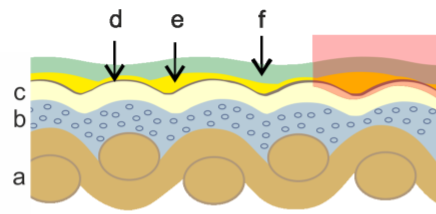

sample $\mathrm{D}+\mathrm{M}$

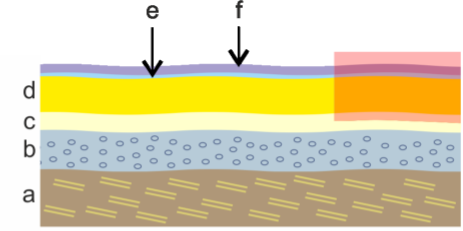

sample $D+A+L$

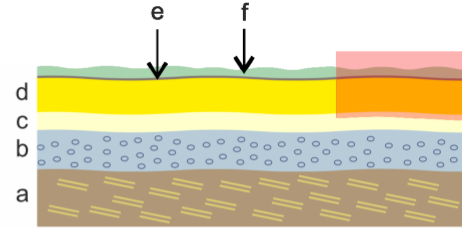

sample $\mathrm{D}+\mathrm{B}$

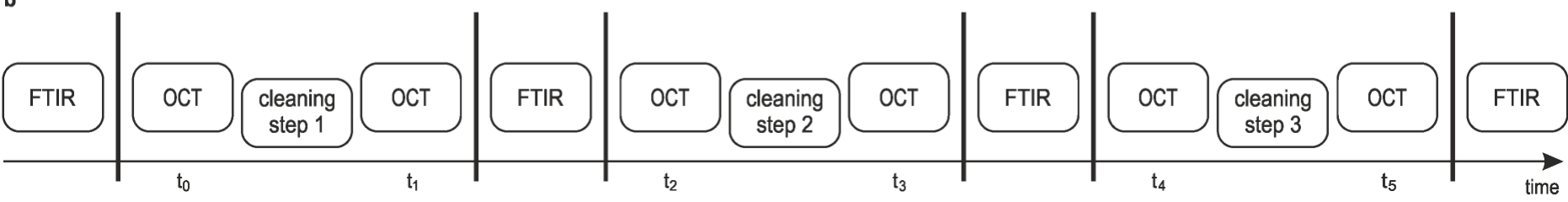

Fig.1 (a) a schematic illustration (not to scale) of strata of samples used, letters refer to layers described in Table 1, depth of OCT imaging marked in pink; (b): measuring procedure projected on the time axis. Vertical lines correspond to translation of the object between the instruments. Coordinates $t_{0}, t_{1}$ etc. show times when 3D OCT data were collected. Surface maps extracted are referred to as surface $\left(t_{0}\right)$, surface $\left(t_{1}\right)$ etc.
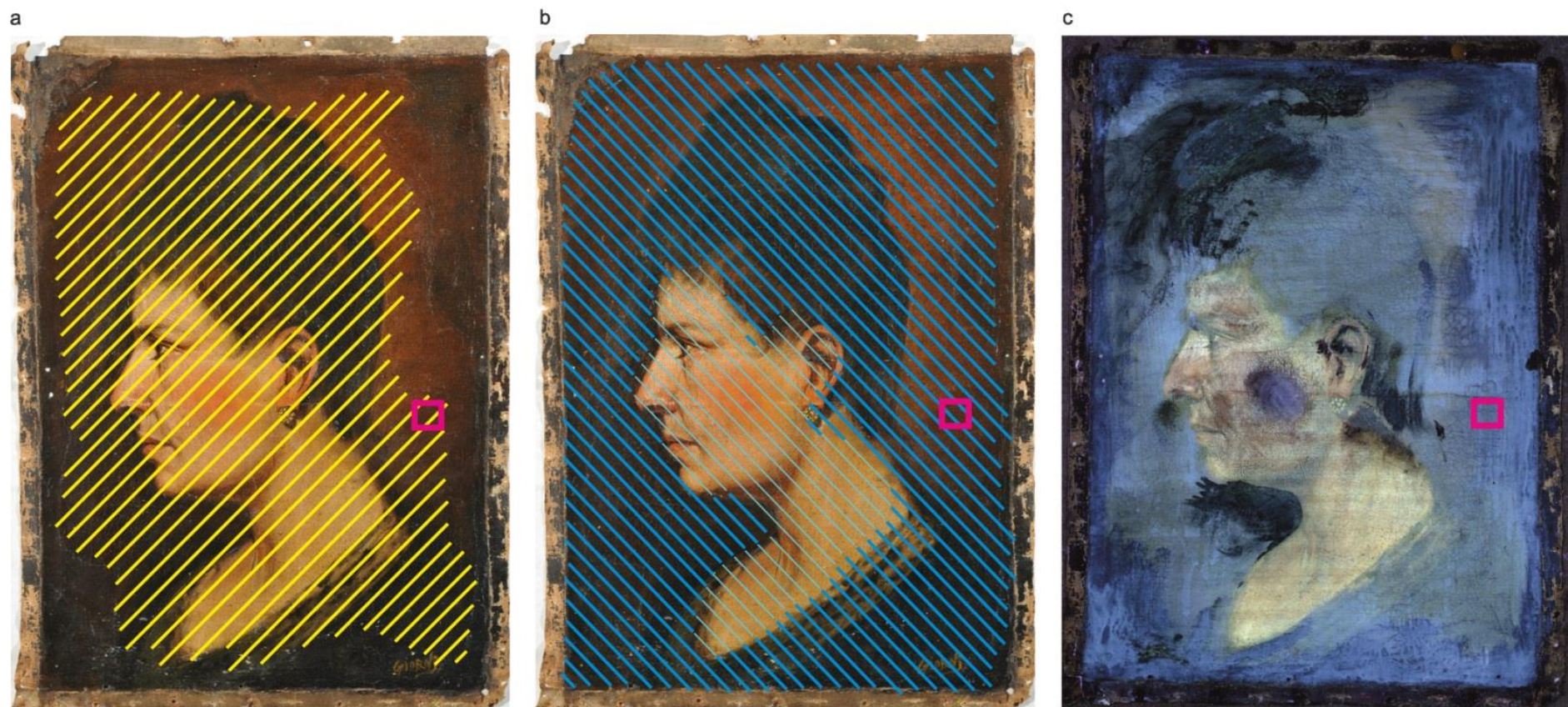

Fig. 2. Portrait of a woman, unknown artist, oil on canvas, $41.5 \times 30 \mathrm{~cm}^{2}$, late $19^{\text {th }}$ century, pink square marks location of the cleaning test area. (a) Visible light photography, yellow lines mark the range of bottom varnish; (b) visible light photography, blue lines mark the range of upper (acrylic) varnish; (c) photography of UV-induced fluorescence.

After completing the research on the samples, the assessment of cleaning tests on the following two historical easel paintings was performed. The first painting was Portrait of a woman (Fig. 2) of unknown origin and history of restoration. Macro XRF scanning (data not shown) revealed a rather simple build-up of ground and paint layers: barium and lead were found in the ready-made ground, unpainted in the area of tacking margins (indicating the use of barium sulphate and lead white). Preparatory drawing had been executed with a chromium-based pigment. Lead, zinc, mercury and iron were identified in the area of the flesh (pointing to the possible occurrence of lead white, zinc white, vermillion, umber), iron in the brown background and hair (umber), titanium in retouchings in the area of the flesh (titanium white). The noninvasive examination by means of OCT and analysis of the photography of UV-induced fluorescence (Fig. 2c) revealed that there are two types of varnishes present on the surface: a bottom one, of yellowish

Microchemical Journal, Vol. 138, May 2018, Pages 7-18

Received 30 August 2017, Available online 17 December 2017, doi: 10.1016/j.microc.2017.12.016

The authors' post-print version 
fluorescence (marked yellow in Fig. 2a) which had been removed from the outskirts of the composition, and an upper one, of blueish fluorescence, applied as one thin layer in the area of the portrayed model's flesh (marked by light blue lines in Fig. 2b) and as at least two thick layers in the background (marked by dark blue lines in Fig. 2b). This procedure, very far from current conservation ethics, was performed by an anonymous in unknown past as a probable attempt of forgery of the signature, which had been previously investigated and reported [21]. The cleaning procedure chosen after preliminary solubility tests was conducted in the area in the dark background (marked by pink square in the figure) in three steps, with a mixture of white spirit and xylene (1:1 pbv) applied by swabbing (3 rolls per step).

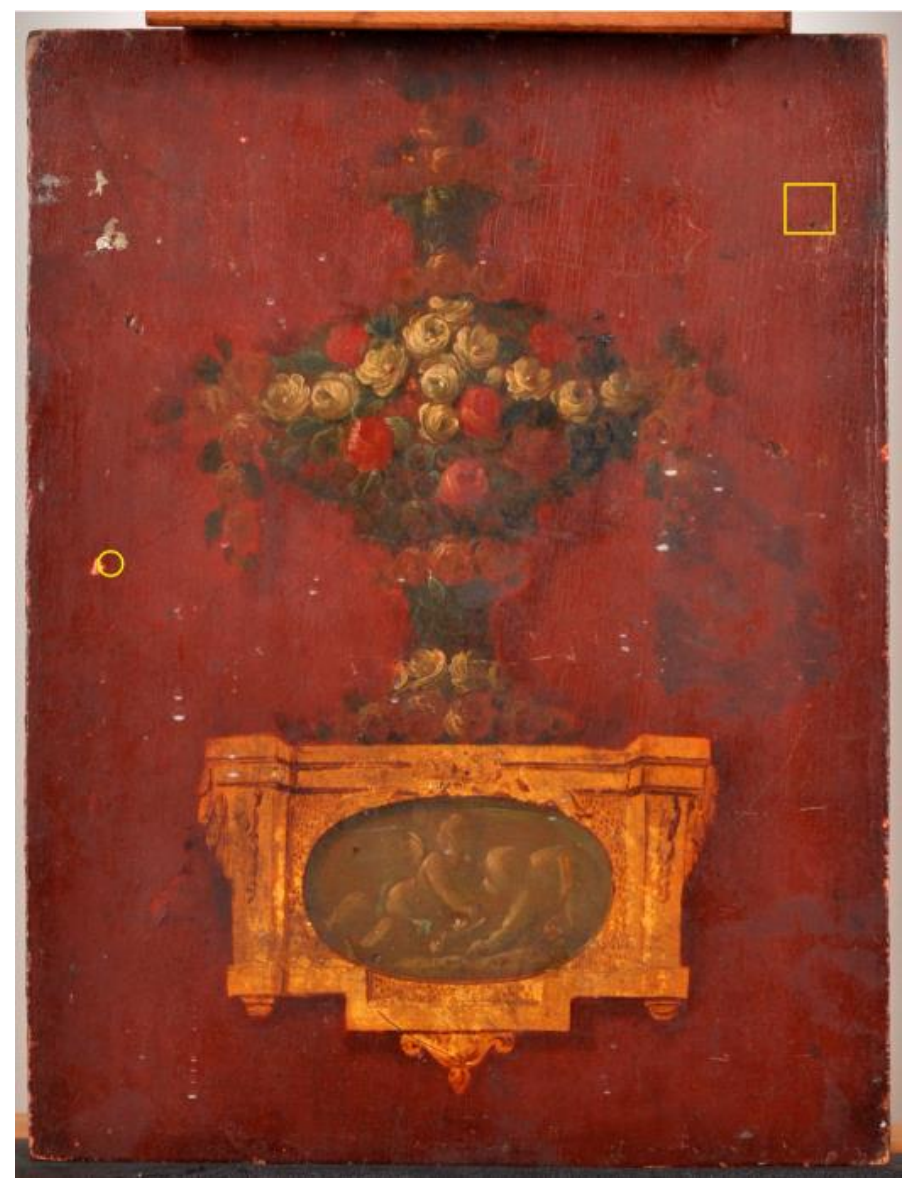

Fig. 3. Floral painting, unknown master, oil on panel, $20.8 \times 27.4 \mathrm{~cm}^{2}$, probably $19^{\text {th }}$ century, study collection Rijksmuseum, Amsterdam. Visible light photograph with the indication of the cleaned test area (yellow square) and the sample collection spot (yellow circle).

The second artwork, the Floral painting was cleaned in the area of the red background (marked by yellow square in Fig. 3 ) in two steps, with ethanol applied by swabbing (10 rolls per step). The cleaning procedure involved rolling a cotton swab mounted on a bamboo stick, moistened with an appropriate solvent or solvent mixture over selected areas $\left(12 \times 12 \mathrm{~mm}^{2}\right)$ of the varnished paint surface to swell and dissolve the varnish layers. 


\subsection{Methods}

\subsubsection{Optical coherence tomography (OCT)}

Optical Coherence Tomography examinations were performed both on models and paintings using a high resolution (ca $3 \mu \mathrm{m}$ axial resolution in air and ca $2 \mu \mathrm{m}$ in a material of refractive index $n_{R}=1.5 ; 15 \mu \mathrm{m}$ lateral resolution) spectral domain OCT instrument [22] with a broad-band superluminescent light source of a spectral range of 770-970 $\mathrm{nm}$ and $0.8 \mathrm{~mW}$ power at the object.

The OCT cross-sectional images (tomograms or B-scans) are presented in false colour scale with colours codified automatically by the software: the areas not-scattering IR radiation (770-970 $\mathrm{nm}$ ), or not reached by it, are shown as black. The layers of increasing, but still moderate scattering properties, are shown in colours from blue to green respectively, whereas the centres of high scattering - from yellow to red. The presented tomograms are vertically stretched for better readability. Scale bars in all the tomograms shown in the figures are equivalent to $100 \mu \mathrm{m}$ (in varnish of $n_{R}=1.5$ ) in both directions.

In this contribution, OCT data are presented not only in the form of cross-sectional images (tomograms), but also as en-face images (differential maps) [23] of examination areas, which enable assessing the bulk of material removed in every step. In order to generate such maps, from 3D OCT data cube collected after every cleaning step and composed of 150 B-scans, a surface profile was extracted. Surface profiles obtained after cleaning are subtracted from the ones acquired before a given step to obtain a map of the material deficit after in this step, or from the first profile, collected before cleaning, to obtain the map of the overall material deficit. Resultant differential maps are coded in false colour scale, the same in all figures.

\subsubsection{Reflection FTIR spectroscopy}

The chemical characterization of the surface compounds on both model samples and easel paintings during the different cleaning steps, was performed by means of a portable FTIR spectrophotometer (ALPHA, Bruker Optics, Germany/USA-MA) equipped with a SiC Globar source, a RockSolid ${ }^{\text {TM }}$ design interferometer (system of parabolic gold mirrors) and a DLaTGS detector. Measurements were carried out by an external reflectance module with an optical layout of $22^{\circ} / 22^{\circ}$ that allows collecting the infrared radiation reflected from a surface located about $1 \mathrm{~cm}$ away. Pseudo-absorption spectra [ $\log (1 / R) ; R=$ reflectance] were obtained from areas of about $5 \mathrm{~mm}$ in diameter, in the spectral range from $7000 \mathrm{~cm}^{-1}$ to $375 \mathrm{~cm}^{-1}$, with a spectral resolution of 4 $\mathrm{cm}^{-1}$ and using average of 186 acquisitions. Spectra from a flat gold mirror were used as background.

\subsection{Combined monitoring procedure}

In the case of the model samples and the Portrait of a woman, to provide reference data for the subsequent FTIR measurements, spectra both for not varnished areas and areas covered by the varnish layer were collected. The resultant spectra are shown in Figs $4 b, 5 b, 6 b, 8 b$, in the Results section. For both the samples and paintings, the areas of the cleaning tests $\left(12 \times 12 \mathrm{~mm}^{2}\right)$ were defined and marked with the use of paper tape (on the model samples) and by 'windows' cut in Mylar foil (in case of the easel paintings). At the beginning of every test, before cleaning, FTIR measurement was performed in the middle of the marked area. Then the object was placed under the OCT head with a scanning beam projecting down. OCT data was collected, and the cleaning procedure was applied. There was a $43 \mathrm{~mm}$ distance from the head lens to the objects' surface, which allowed the conservator to roll cotton swabs on the painting without moving the OCT head. Subsequently, the OCT data were collected again. This was necessary for the repeatability of scans and 
thus for a precise comparison between those scans obtained before and after treatment. Then the object was moved to perform FTIR analysis on the same marked area. Afterwards it was reinstalled again under OCT head for the next cleaning step. The described procedure was repeated for as many steps as there were needed. The whole procedure is shown at the time axis in Fig. $1 \mathrm{~b}$, where vertical lines mark transferring of the object between installations and $t$ coordinates mark subsequent OCT data acquirements. Given the comparatively large size of the FTIR measuring spot, repeatable repositioning of the object under the FTIR head was not problematic. Conversely, for the OCT measurements a precision at micrometric scale is needed especially after different cleaning steps (mainly for generation of differential maps). The coarse reposition was performed with mechanical limiters preventing rotation of the object and repeating $X, Y$ position to about $50 \mu \mathrm{m}$ but with no control of elevation of the object. The desired micrometric precision: better than the distance between $B$-scans in $Y$ direction $(80 \mu \mathrm{m})$, better than twice the lateral resolution in $X$ direction and better than the twice the axial resolution (in air) in $Z$ direction was achieved by software matching of the B-scans (separately for the first and the last in the cube) taken from the OCT data collected before and after repositioning. Obtained translations were applied to data to ensure proper alignment of the surface profiles. The same procedure was applied to OCT data acquired directly before and after cleaning to correct for possible small displacement of the object during mechanical action.

\section{Results}

In the herein presented tomograms the beam of light approaches the object from the top and therefore the uppermost medium in all the tomograms is air above the object (seen as black). The surface of the object is the air-varnish interface, visible as a strong green line. The varnishes are presented as black/dark blue stripes, and the interfaces between varnish layers are usually visible as thin blueish lines (the existence of dirt between varnish layers enhances their distinguishability in OCT). Paint layers are visible as 'cloudy' blueish structures, and their permeability to near infrared radiation is usually limited to thin or uppermost layers.

Reflection FTIR spectra are reported at different steps of cleaning in order to compare/combine the information. As for the models, spectra collected on the samples prepared with various final layers (no varnish, one layer of varnish, two layers of different varnishes) are also shown for facilitating the interpretation. Here the probing radiations are typically confined to the upper part, although, depending on the spectral range, spectral properties of the different paints and their thickness, also bands from inner layers may emerge. The spectral profiles collected in reflection mode are composed of both specular and diffuse reflected components and thus highly distorted: the specular reflection typically appears with derivative or reststrahlen (inverted shape) features while relative intensity is changed by the diffuse component [24].

\subsection{Combining OCT and FTIR for assessing cleaning: study of models}

\section{Sample D+A: monitoring the progressive removal of synthetic resin (acrylic) and natural (dammar)}

The OCT tomogram and FTIR spectrum collected on the D+A model before the cleaning test are shown in figure $4 \mathrm{a}$ and $4 \mathrm{~b}$. Two varnish layers, the upper being fully transparent (acrylic) and lower slightly scattering (dammar), are clearly distinguishable in the tomogram (Fig. 4a). Reflection FTIR spectrum (Fig. 4b,d,f,h, grey line) collected from the same area shows the characteristic bands at $1240 \mathrm{~cm}^{-1} \mathrm{v}(\mathrm{C}-\mathrm{O}-\mathrm{C}), 1170 \mathrm{~cm}^{-1} \mathrm{v}(\mathrm{C}-\mathrm{C})$ and $1150 \mathrm{~cm}^{-1} \mathrm{v}(\mathrm{C}-\mathrm{O})$ of an acrylic component [25]. After the first cleaning step, OCT notes thinning of the top (acrylic) varnish layer, while in the FTIR examination significant changes do not emerge in comparison to the 
uncleaned surface, confirming the persistence of the acrylic varnish (Fig. 4c,d). The acrylic varnish is no longer distinguishable in the OCT tomogram acquired after the second cleaning step (Fig. 4e), and the dammar layer appears uncovered. Interestingly, FTIR spectrum at the same step (Fig. 4f) shows no evidence of the typical spectral features of the natural resin, generally identified by stretching of the carbonyl group at about $1714 \mathrm{~cm}^{-1}$ and by the signals at $1474 \mathrm{~cm}^{-1} \delta_{\mathrm{s}}\left(\mathrm{CH}_{3}\right)$, at $1383 \mathrm{~cm}^{-1} \delta_{\text {as }}\left(\mathrm{CH}_{2}\right)$ and $1225 \mathrm{~cm}^{-1} \mathrm{v}(\mathrm{C}-\mathrm{C})$. On the other hand, the infrared spectral pattern reveals that residues of the acrylic varnish are still present explaining the difficulty in detection of the dammar varnish. Nevertheless, the appearance at low frequencies of a band ascribable to titanium white [26] (featuring a reststrahlen shape), not clearly evident in the presence of dammar (Fig. 4b, black line), suggests the removal or thinning of this natural varnish layer. Acrylic residues are also found in the FTIR spectrum acquired after the final cleaning step along with a further intensity increase of titanium white signal (Fig. 4h). In detail, this evidence could be correlated to exposing the titanium white paint layer with the risk of some abrasion of the paint as confirmed by the OCT measurement. In fact, in the last tomogram collected (Fig. $4 \mathrm{~g}$ ), some remains of varnish (probably the bottom layer of dammar) are still visible in concaves along brushstrokes, while the paint layer seems to be affected. From the study of this specific multi-layered paint model, OCT permitted to distinguish the two varnish layers. On the other hand, the spectroscopic technique showed a higher sensitivity towards the acrylic detection: the signal from an acrylic varnish was present also after the second and third cleaning steps, whereas it was not seen in the OCT examination. This could have been either because after the second cleaning step the acrylic layer was thinner than the OCT axial resolution (ca $2 \mu \mathrm{m}$ ) or, more likely, it was present only as residues in the porous structure of the paint rather than in the form of a layer. 

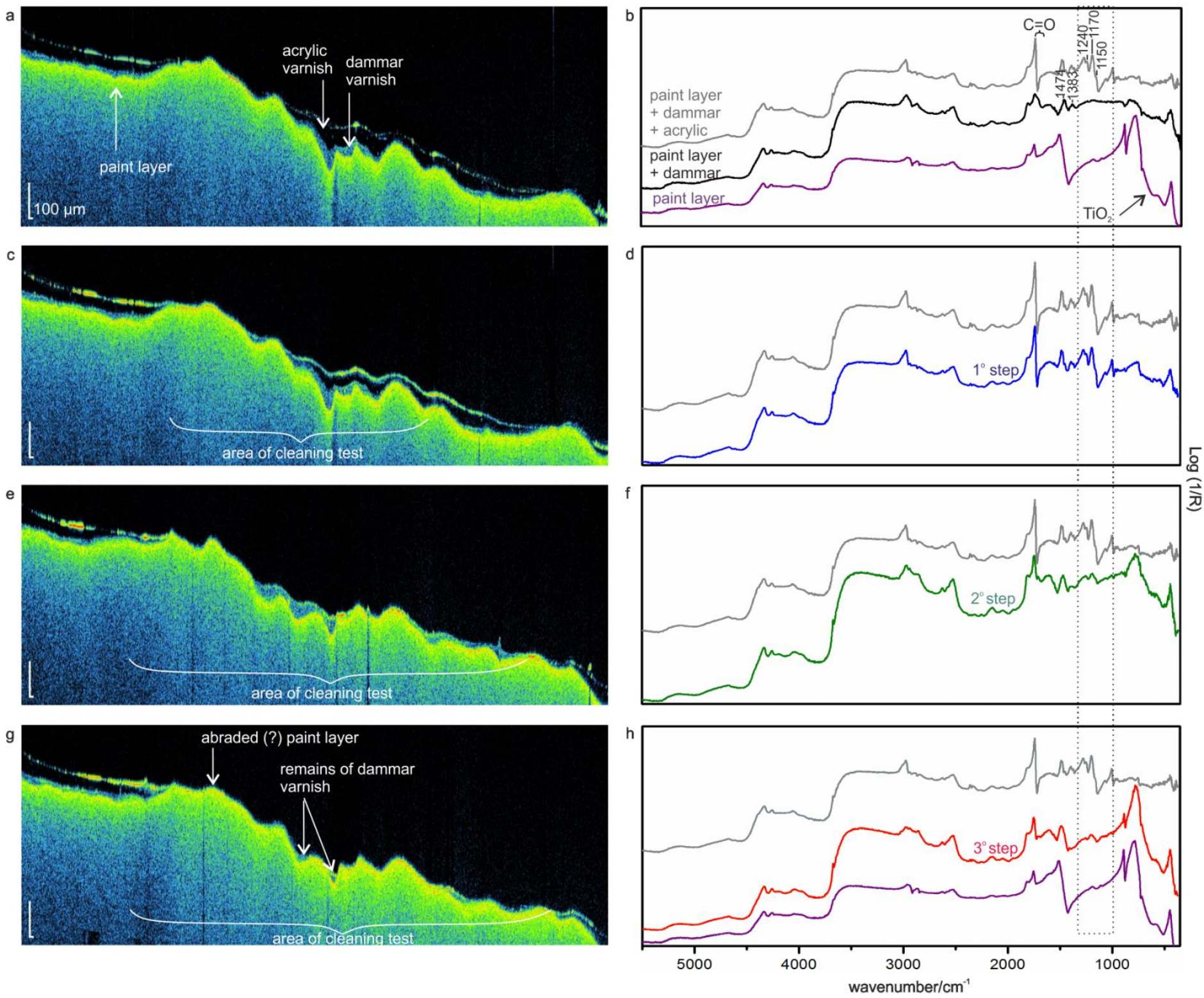

Fig. 4. Sample D+A. OCT tomograms: (a) before cleaning, at $t_{0}$ (varnish layer thickness: dammar: 15-60 $\mu \mathrm{m}$, acrylic: 30-50 $\mu \mathrm{m})$; (c) after step 1, at $t_{1}$; (e) after step 2, at $t_{3}$; $(\mathrm{g})$ after step 3, at $\mathrm{t}_{5}$; total length of the OCT tomograms is $12 \mathrm{~mm}$. Reflection FTIR spectra: (b) of unvarnished (violet line) and varnished (dammar - black line, dammar + acrylic - grey line) paint layer; (d) after step 1; (f) after step 2; (h) after step 3. In (d,f,h) FTIR spectra of varnished and unvarnished (only in (h)) paint layer are also reported for comparison.

\section{Sample D+M: monitoring the progressive removal of microcrystalline wax and natural resin (dammar)}

The model sample was prepared with use of the same paint layer and dammar varnish the sample $D+A$, but covered with microcrystalline wax. In the OCT tomogram of the uncleaned area (Fig. 5a), differently from the case of the sample $D+A$, the underlying dammar layer is thicker in comparison to the overlaid layer. This partially explains why the dammar layer was already detectable by the FTIR analysis before the cleaning (Fig. 5b). In details, the absence of the ester functionality in the microcrystalline wax allows detecting a broadening of the oil binder carbonyl band (centred at $\sim 1740 \mathrm{~cm}^{-1}$ ) due to the contribution of the natural varnish ( $\mathrm{C}=\mathrm{O}$ stretch at slightly lower frequencies). Furthermore, the spectrum shows the marker bands referable to a wax at $2954 \mathrm{~cm}^{-1}$ (asymmetric stretching $\mathrm{CH}_{3}$ ), 2922 and $2853 \mathrm{~cm}^{-1}$ (asymmetric and symmetric 
stretching $\mathrm{CH}_{2}$, respectively), $1474 \mathrm{~cm}^{-1}$ assigned to $\mathrm{CH}_{2}$ scissor deformation vibrations, as well as the doublet at 732 and $716 \mathrm{~cm}^{-1}$ due to the $\mathrm{CH}_{2}$ rocking mode [27]. The signals of $\mathrm{CH}_{2}$ deformation modes (1383 and 1474 $\mathrm{cm}^{-1}$ ), instead, are present in both wax and natural varnish [10], therefore they cannot be used as dammar marker bands. After the first cleaning step, in the OCT investigation the thin microcrystalline layer is not visible anymore (Fig. $5 \mathrm{c}$ ). Wax residues are detected in the infrared spectrum, shown in figure $5 \mathrm{~d}$, especially through the sharp profiles and strong intensity of the hydrocarbons signals, as well as from the still visible doublet at lower wavenumbers. Furthermore, a weak increase of the titanium white band can be observed, while the broadening of the band at $1473 \mathrm{~cm}^{-1}$ suggests a possible contribution of the dammar. Considering the final cleaning step, from FTIR analysis a spectrum very similar to that acquired on the unvarnished paint layer, without any marker bands ascribable to possible varnish/wax residues, is obtained (Fig. 5f). Conversely, in the OCT tomogram, shown in figure $5 \mathrm{e}$, dammar is still evident, particularly in depressions along the brushstrokes of the painted surface.

In conclusion, the investigations performed on this area allow exploring the possibility to detect varnish residues by both OCT and FTIR. Additionally, in this case it was possible to identify the underlying dammar layer on an uncleaned area by FTIR spectroscopy.
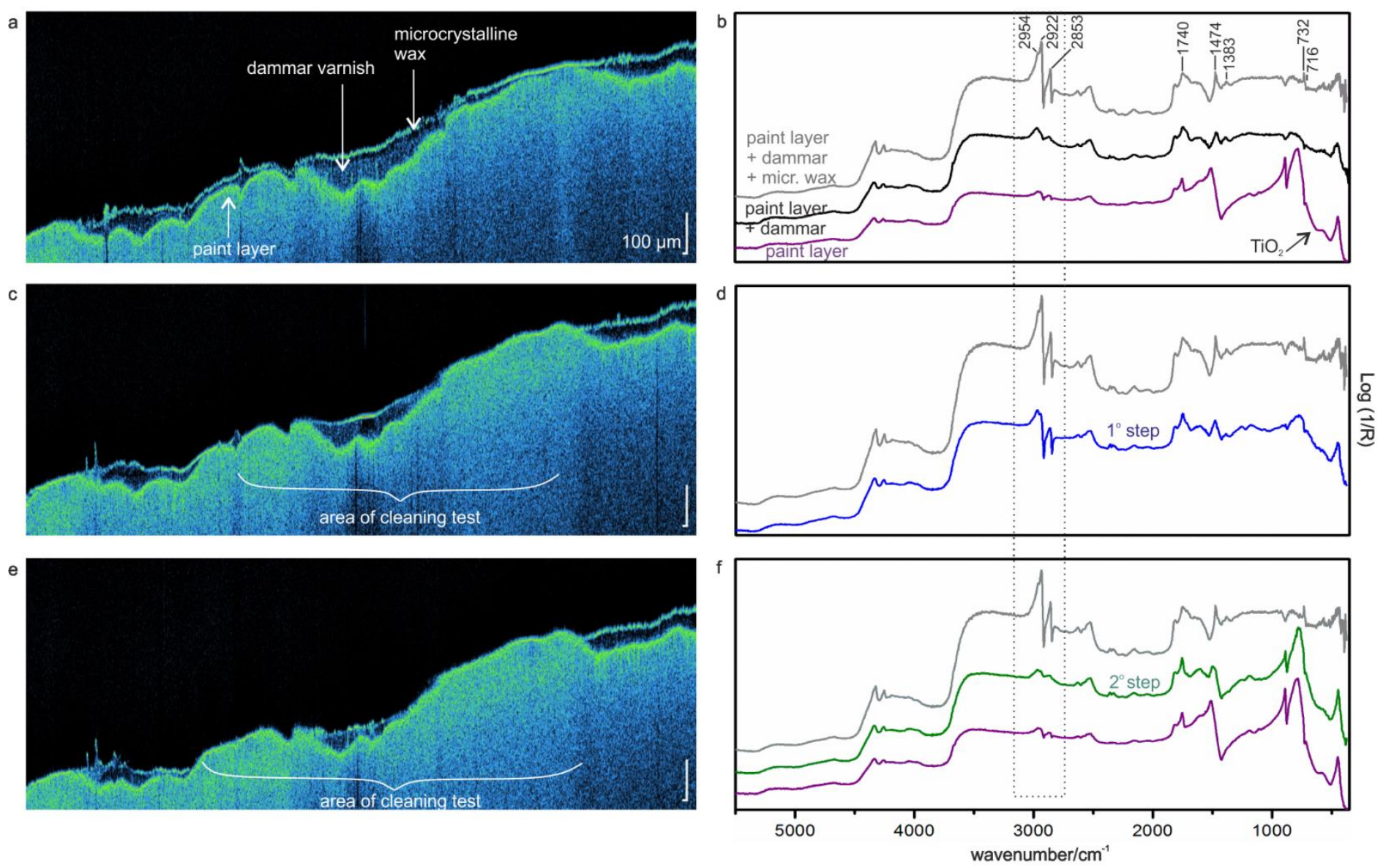

Fig. 5. Sample D+M. OCT tomograms: (a) before cleaning, at $t_{0}$ (varnish layer thickness: dammar: 15-20 $\mu \mathrm{m}$, microcrystalline wax: 8-50 $\mu \mathrm{m}$ ); (c) after step 1, at $t_{1}$; (e) after step 2, at $t_{3}$; length of OCT tomograms is $12 \mathrm{~mm}$. Reflection FTIR spectra: (b) of unvarnished (violet line) and varnished (dammar - black line, dammar + microcrystalline wax - grey line) paint layer; (d) after step 1; (f) after step 2. In (d) and (f) FTIR spectra of varnished and unvarnished (only (f)) paint layer are also reported for comparison. 
In the OCT tomogram (Fig. 6a) collected on the uncleaned area of sample $D+A+L$ it is possible to distinguish a single layer of non-scattering Laropal A81 varnish (visible as a black stripe) on top of a weakly scattering (coded in blueish hue) bottom layer of matt dammar varnish covered with an extremely thin layer of matt acrylic varnish. Both matt varnishes comprise colloid silica, which causes scattering patterns in the OCT images. The acrylic is not visible as a layer separate from dammar, possibly because it is too thin to be recognisable in the OCT examination due to the application by spraying and/or because it had been applied on very fresh dammar and had been melted into it. The reflection FTIR spectrum collected before the cleaning (Fig. 6b, grey line) is dominated by several signals in the range between $1740-1010 \mathrm{~cm}^{-1}$ arising from the urea-aldehyde resin Laropal A81. Specifically, two strong stretching vibration modes of carbonyl groups can be observed at $1736 \mathrm{~cm}^{-1}$ and at $1655 \mathrm{~cm}^{-1}$. The latter is due to the amide I of the urea content in Laropal A81. Furthermore, the derivative-shape band at about $1488 \mathrm{~cm}^{-1}$ assigned to the bending vibration of the methyl group and a strong signal in the fingerprint region at $1088 \mathrm{~cm}^{-1}$ (Fig. 6b, grey line) are also related to the urea-aldehyde resin [10].

After the first cleaning test, in the OCT tomogram (Fig. 6c) the alteration of the sample's structure is visible: the surface becomes less smooth and some decrease of the thickness the Laropal A81 layer is visible. In the FTIR spectrum (Fig. 6d, blue line) only an intensity decrease of the amide I carbonyl band at $1655 \mathrm{~cm}^{-1}$ could be noticed. After the second cleaning step, in the OCT tomogram (Fig. 6e) the dammar layer becomes uncovered. The uncovering of the natural varnish is confirmed by FTIR, through the appearance of a peak at $1714 \mathrm{~cm}^{-1}$ correlated to the carbonyl group of terpenic structures (Fig. 6f, green line). Furthermore, the identification of the matt varnish is facilitated by the observation of two intense derivative-shape bands around at $1108 \mathrm{~cm}^{-1}$ and $474 \mathrm{~cm}^{-1}$ ascribable to Si-O antisymmetric stretching and O-Si-O bending modes, respectively, of the silica component (Fig. 6b, violet line) $[24,28]$ present in the varnish itself (see Table 1). However, the amide I carbonyl band and the signal at $1488 \mathrm{~cm}^{-1}$, both of Laropal A81, are still present highlighting the possible persistence of residues of this synthetic varnish. 

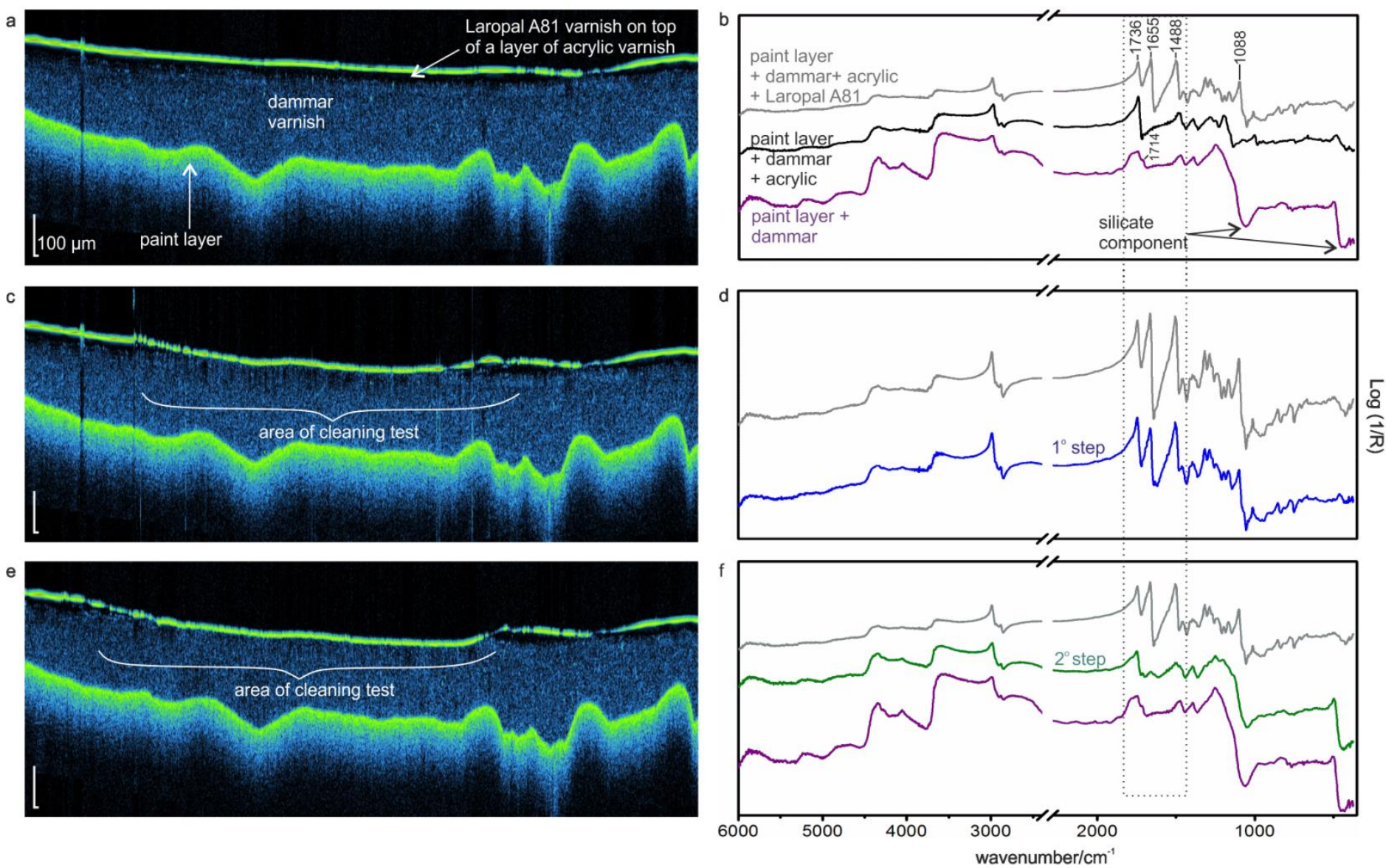

Fig. 6. Sample $D+A+L$. OCT tomograms: (a) before cleaning, at $t_{0}$ (varnish layer thickness: dammar: 200-260 $\mu \mathrm{m}$, acrylic and Laropal A81: ca $25 \mu \mathrm{m}$ ); (c) after step 1, at $\mathrm{t}_{1}$; (e) after step 2, at $\mathrm{t}_{3}$; total length of the OCT tomograms is $12 \mathrm{~mm}$. Reflection FTIR spectra: (b) of varnished (dammar - violet line, dammar + acrylic - black line, dammar + acrylic + Laropal A81 - grey line) paint layers; (d) after step 1; (f) after step 2. In (d) and (f) FTIR spectra of varnished paint layer are also reported for comparison.

\section{Sample $D+B$ : monitoring the selective removal of beeswax from dammar varnish}

In the sample $D+B$, the application of an intermediate layer of soot between beeswax and dammar allows to better visualise in the OCT cross-sections the boundary between these two layers (see tomogram in figure 7a). From the FTIR data obtained before the cleaning only the presence of beeswax is clearly confirmed (Fig. 7b). The infrared features of the beeswax are mostly the same as found for the microcrystalline type: i.e. the stretching vibration modes of methyl $\left(2954\right.$ and $\left.2922 \mathrm{~cm}^{-1}\right)$ and methylene $\left(2853 \mathrm{~cm}^{-1}\right)$ groups, the $\mathrm{CH}_{2}$ bending at $1474 \mathrm{~cm}^{-1}$, as well as the doublet at lower frequencies $\left(732\right.$ and $716 \mathrm{~cm}^{-1}$ ) due to in-plane rotation of linear long carbon chains $\left(\delta\left(\mathrm{CH}_{2}\right) \mathrm{n}\right)$ [29]. However, the two wax types can be distinguished by the carbonyl ester bond identified by the band at about $1740 \mathrm{~cm}^{-1}$, present exclusively in the beeswax. After the first cleaning step, the combination of OCT tomogram and FTIR spectrum shown in figure $7 c, d$ reveals the beeswax removal in the centre of the scanned area, which is better visualised in a material removal map by OCT, and confirmed by FTIR. More in details, the differential (material removal) map by OCT (Fig. $7 \mathrm{~g}$ ) enables the assessment of thickness of the removed material as in the range from 30 to $70 \mu \mathrm{m}$ within the cleaned area and a presence of a tideline, an elevated ring of the material displaced during its removal by swabbing (up to $40 \mu \mathrm{m}$ over the original painting surface). In the FTIR spectral pattern (Fig. 7d, blue line) a strong intensity decrease of the beeswax marker bands is observed. The occurrence of the signals at $1225 \mathrm{v}(\mathrm{C}-\mathrm{C})$ 
and $1382 \delta_{\text {as }}\left(\mathrm{CH}_{2}\right)$, and the shape variation of the peak at $1474 \mathrm{~cm}^{-1} \delta_{\mathrm{s}}\left(\mathrm{CH}_{3}\right)$ reveal the uncovering of the dammar layer underneath [10]. Furthermore, the broadening of the carbonyl wax band with the appearance of a shoulder at lower frequencies (about $1708 \mathrm{~cm}^{-1}$ ), as well as the evidence of a silicate component (see Table 1) further confirm the detection of this resin. These spectral features of the matt dammar layer are clearly observed in the spectrum acquired after the second cleaning step (Fig. 7f, green line), while the doublet typical of beeswax disappears; however the sharp profile of the hydrocarbons and the carbonyl band suggest the persistence of beeswax residues. In this cleaning step OCT reveals some further wax removal only in the outskirts of the cleaned area, noticed both in the tomogram (Fig. 7e) and in the material removal map (Fig. 7h). It is evident from the map that there was no further material removal from the centre of the cleaned area. This information enables assessing the cleaning process as selective.
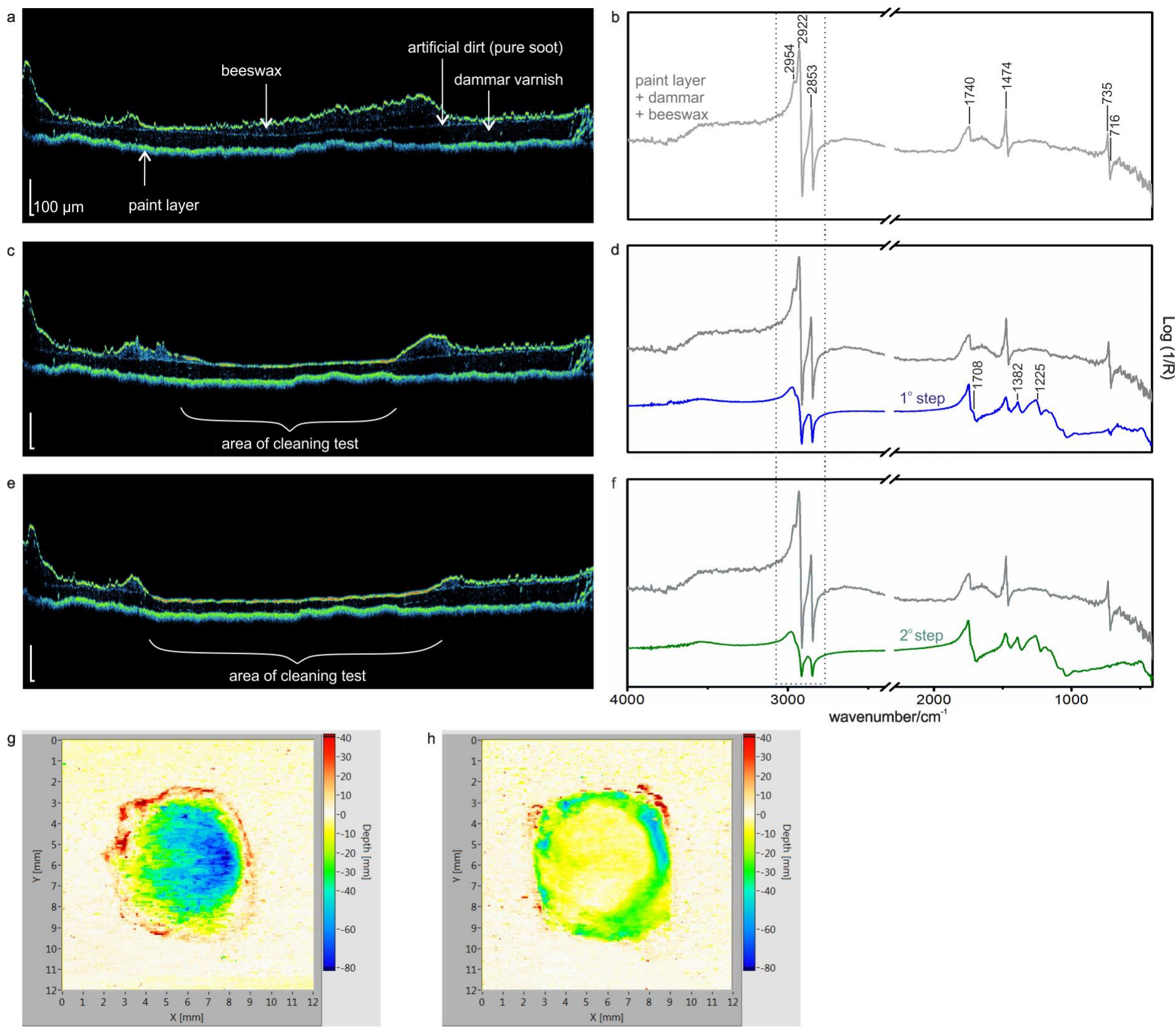

Fig. 7. Sample D+B. OCT tomograms: (a) before cleaning, at $t_{0}$ (varnish layer thickness: dammar: $65-90 \mu \mathrm{m}$, beeswax: $35-$ $140 \mu \mathrm{m})$; (c) after step 1, at $t_{1}$; (e) after step 2, at $t_{3}$; total length of the OCT tomograms is 12 mm. Reflection FTIR spectra: (b) of varnished (dammar + beeswax - grey line) paint layer; (d) after step 1; (f) after step 2. In (d) and (f) FTIR spectrum of varnished paint layer is also reported for comparison. OCT differential maps: (g) of material deficit after

Microchemical Journal, Vol. 138, May 2018, Pages 7-18

Received 30 August 2017, Available online 17 December 2017, doi: 10.1016/j.microc.2017.12.016

The authors' post-print version 
step 1 calculated from subtraction of surfaces recovered at $t_{1}$ and $t_{0} ;(h)$ of material deficit after step 2 calculated from subtraction of surfaces recovered at $t_{3}$ and $t_{2}$.

\subsection{Easel paintings}

\subsubsection{Portrait of a woman}

In the case of the Portrait of a woman (Fig. 2) FTIR measurements performed before the cleaning tests identified the upper varnish as acrylic (Fig. 2b, blue hatching and Fig. 8b, grey line). The aim of the cleaning procedure in this case was to selectively remove only the non-original, acrylic varnish and to leave the bottom (and possibly primary) varnish intact. On the selected, yet uncleaned area, two varnish layers are clearly distinguishable by OCT (Fig. 8a), while the acrylic varnish is unambiguously identified by FTIR (Fig. 8b, grey line). After the first cleaning step, an intensity decrease of the signals arising from this synthetic varnish, especially in the fingerprint region (bands at 1170 and $1150 \mathrm{~cm}^{-1}$ ), is evident (Fig. 8d). The lower relative intensity of the acrylic bands can be correlated to a significant thinning of this layer as proved by the OCT tomogram collected after step 1 (Fig. 8c). After the second cleaning test, the OCT investigation reveals a complete removal of acrylic and uncovering the underlying varnish layer (Fig. 8e). In the FTIR spectra collected after both the first and second cleaning steps (Fig. 8d,f), the presence of a natural varnish is discernible only by the carbonyl peak at about $1714 \mathrm{~cm}^{-1}$. Furthermore, the second cleaning step leads to a further decrease of the acrylic signals, mostly the carbonyl band at $1740 \mathrm{~cm}^{-1}$, as well as to the appearance of infrared features ascribable to the pigments coming from the paint and ground layers. In particular, the inverted band at about $1113 \mathrm{~cm}^{-1}$ and the derivative-shape signals at 670 and $600 \mathrm{~cm}^{-1}$, assigned to the antisymmetric stretching $\left(v_{3}\right)$ and bending $\left(v_{4}\right)$ modes of $\mathrm{SO}_{4}{ }^{2-}$ respectively [10], suggest the presence of a sulphate compound identified as barium sulphate through the detection of its diagnostic combination bands $\left(v_{1}+v_{3}\right)$ in the range between 2500-1900 $\mathrm{cm}^{-1}$ [24]. Moreover, at lower frequencies the inverted bands around $1000 \mathrm{~cm}^{-1}$ and $430 \mathrm{~cm}^{-1}$ associated with a silicate component, probably of an earth pigment, can be distinguished. The appearance of the signal at about $1320 \mathrm{~cm}^{-1}$, instead, can be correlated to the $v_{s}(\mathrm{CO})$ of calcium oxalates [30], most likely resulting from an oxidative degradation of the paint materials [31]. Following the third cleaning test, the complete removal of acrylic is confirmed by both analytical techniques (Fig. 8g,h). In the FTIR spectral pattern acrylic residues are not detected, while a lipid component appears more evident. The latter can be ascribable to a natural oleoresin varnish or more likely to the oil binder of the paint layer underneath. As a matter of fact, the observation of the signals from an earth pigment and barium sulphate indicates a spectral contribution from the paint and ground layers. The removal of the upper varnish leads to an increase of the signal from calcium oxalates. Moreover, the presence of these alteration compounds probably explains the broadening of the carbonyl band and the occurrence of a signal at 3395 $\mathrm{cm}^{-1}$ in the $\mathrm{v}(\mathrm{OH})$ region [30].

The effectiveness of the varnish removal procedure can be directly assessed from the OCT differential maps. During the first step ca $40 \mu \mathrm{m}$ of the varnish have been removed - the varnish was thinned fairly evenly (Fig. $8 \mathrm{i})$. The map in figure $8 \mathrm{j}$ reveals that in step 2 a little varnish was removed from the centre of the test spot. In step 3 (Fig. 8k) no varnish was removed from the centre and only some material from the perimeter was taken off and thus the goal of selective cleaning is achieved. The sequence of the OCT differential maps (Fig. $8 \mathrm{i}, \mathrm{j}, \mathrm{k})$ give valuable insight into the dynamics of the cleaning process and confirm that the bottom varnish is not affected by the chosen solvent composition, so that the procedure can be considered selective. 

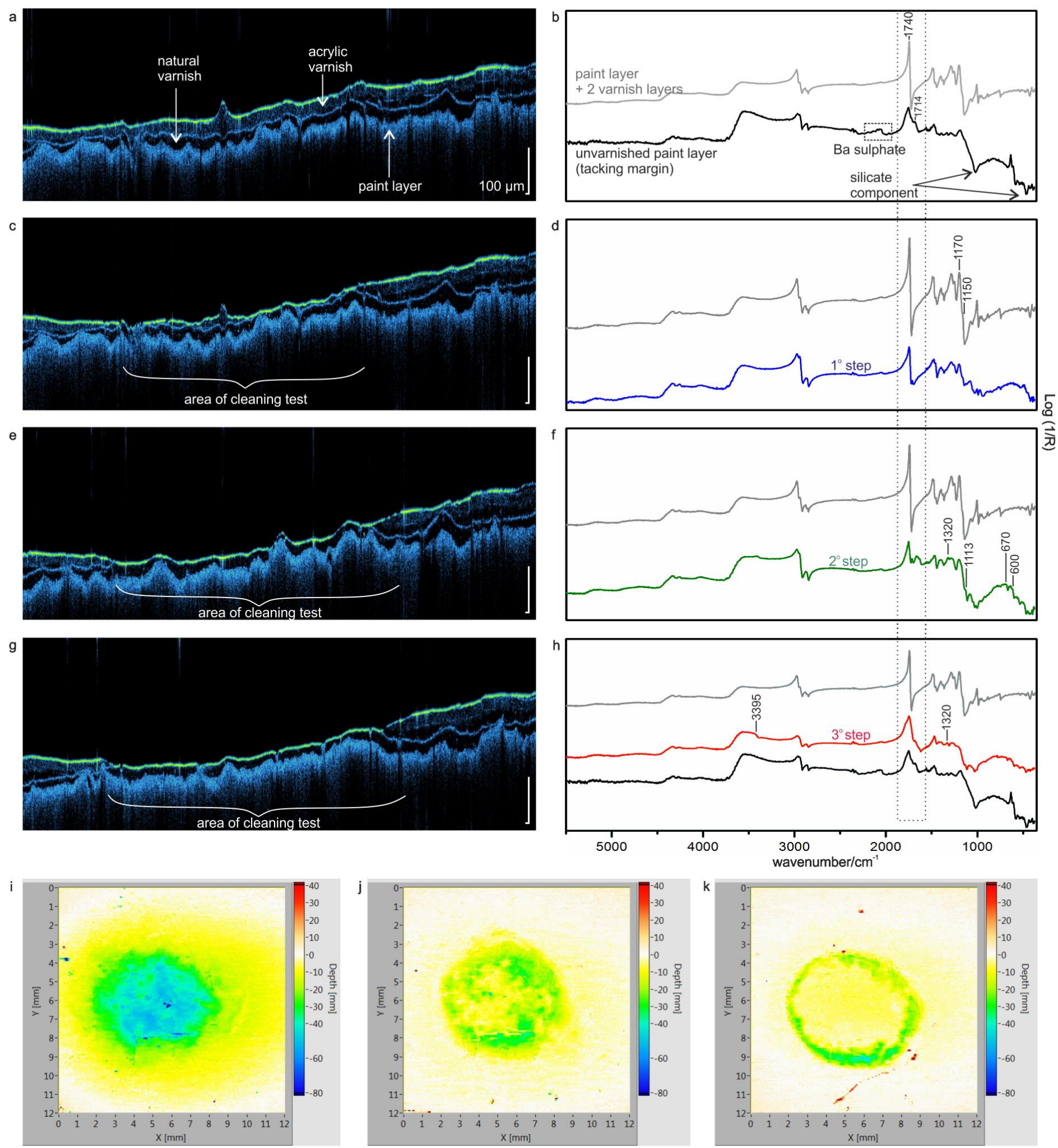

Fig. 8. Portrait of a woman. OCT tomograms: (a) before cleaning, at $t_{0}$; (c) after step 1 , at $t_{1}$; (e) after step 2 , at $t_{3}$; (g) after step 3, at $t_{5}$; total length of OCT tomograms is $12 \mathrm{~mm}$. Reflection FTIR spectra: (b) of varnished (grey line) and unvarnished (black line) paint layer; (d) after step 1; (f) after step 2; (h) after step 3. In (d,f,h) FTIR spectrum of varnished and unvarnished (only (h)) paint layer is also reported for comparison. OCT differential maps of material deficit after consecutive steps: (i) after step 1 - calculated from subtraction of surfaces recovered at $t_{1}$ and $t_{0}$; (j) after step 2 calculated from subtraction of surfaces recovered at $t_{3}$ and $t_{2} ;(k)$ after step 3 - calculated from subtraction of surfaces recovered at $t_{5}$ and $t_{4}$. 


\subsubsection{Floral painting}

The Floral painting (Fig. 3) was chosen as a final test object to be presented in this study, because of its buildup of layers, complex, yet typical for historical paintings bearing signs of many restoration attempts. Sample cross-section analysis (Fig. 9a) in combination with OCT tomograms (Fig. 9b,c,d,e) points out that multiple varnish layers and extensive overpaint was applied on the panel in the past. By means of the OCT technique it is possible to visualise layers down to the primary paint. OCT analysis makes clear that the build-up of layers is very similar in all the areas examined, the thickness of upper varnish layers, however, varies significantly. For a sake of direct comparison with the cross-section photograph, the OCT tomogram obtained at the sample collection spot (Fig. 9b) is given in the same scale. In the cross-section presented in figure 9a and the relevant tomogram (Fig. 9b) the stratigraphy can be described as follows. On the whitish ground (layer 1) the original red background paint (layer 2, vermilion, confirmed by XRF) was applied very thinly. On top of the original paint layer, three thin varnishes (with an overall thickness of ca $25 \mu \mathrm{m}$ ) can be discriminated in the cross-section (layers $3,4,5$ ). In the OCT tomograms however, these varnishes cannot be separated but are visualised as a single layer. The overpaint (layer 6, red iron oxide, identified by FTIR, confirmed by XRF and SEM-EDX) applied over the entire background is covered with two layers of natural resin varnish (layers 7 and 9, established by FTIR) separated by a dirt layer in between (layer 8), which is confirmed by OCT. On top of the surface a layer of beeswax is detected embedded with dirt (layer 10, identified by FTIR) visible in the OCT examination as a thin and slightly scattering layer.

The goal of the cleaning experiment was to selectively remove the non-original varnishes, step by step. It is worthwhile to note that preliminary varnish removal tests revealed that it was difficult to differentiate the red earth overpaint in the Floral painting from the primary vermillion paint layer with routinely used visual examination techniques, such as microscope and UV-induced fluorescence observation. Therefore, employing other cleaning assessment tools was desirable from the conservator's point of view in this case. Here, the removal of only the two uppermost layers is presented, that is beeswax with embedded dirt (layer 10 in Fig. 9a,b) and one of the layers of secondary natural varnish (layer 9 in Fig. 9a,b). Before the cleaning, in the OCT tomogram (Fig. 9c) three superficial transparent layers with an overall thickness of $70 \mu \mathrm{m}$ are visible over the overpaint layer. The FTIR analysis of an uncleaned spot (Fig. $9 \mathrm{f}$, grey line) identified beeswax and calcium oxalates (signal at $\left.1320 \mathrm{~cm}^{-1}\right)$. Moreover, the bands of $\mathrm{SO}_{4}{ }^{2-}$ vibration modes $\left(v_{3}\right.$ and $\left.v_{4}\right)$ and specially the $\mathrm{OH}$ stretching signals at 3398 and $3555 \mathrm{~cm}^{-1}$ reveal the presence of deposited/migrated gypsum [32]. After the first cleaning step, OCT tomogram (Fig. 9d) shows the removal of uppermost layer of beeswax with embedded dirt (which corresponds to layer 10 in figure 9a,b). It is worthwhile to note that beeswax, as a slightly scattering material, is easily distinguishable from natural varnishes in OCT tomograms, in this case, it is however quite thin. The second uppermost layer is one of the layers of secondary natural varnish (layer 9 in figure $9 a, b)$ and it was removed in step 2, what is clearly visible in the tomogram (figure 9e). OCT differential maps (figure 9g,h) show the removal of circa $20 \mu \mathrm{m}$ of thickness of varnish in step 1, and 40-50 $\mu \mathrm{m}$ after two steps of cleaning. The FTIR investigation performed after the second cleaning step (Fig. 9f, green line) confirmed the beeswax removal. This lack of beeswax allows to better recognize a carbonyl functionality $\left(\mathrm{C}=\mathrm{O}\right.$ stretching at about $1740 \mathrm{~cm}^{-1}$ ) that can be associated with the natural varnish and/or the oil binder. In this case, indeed, the presence of an underlying oil based paint layer makes more difficult the distinction of the varnish. Therefore, to detect the natural varnish the OCT investigation was fundamental, while the infrared analysis, aside from the beeswax identification, allowed to obtain additional information related to the removal monitoring of superficial gypsum and calcium oxalates. 

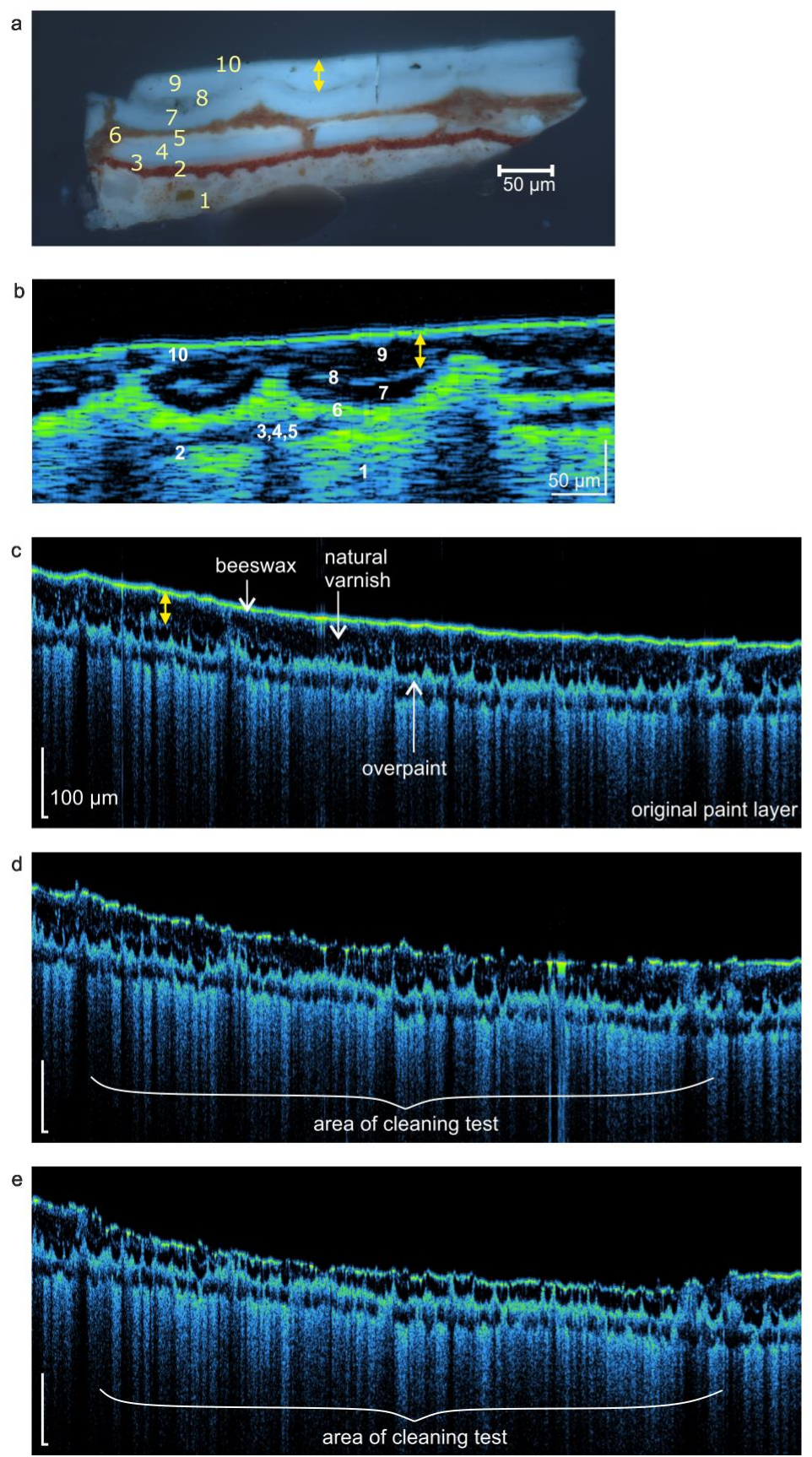

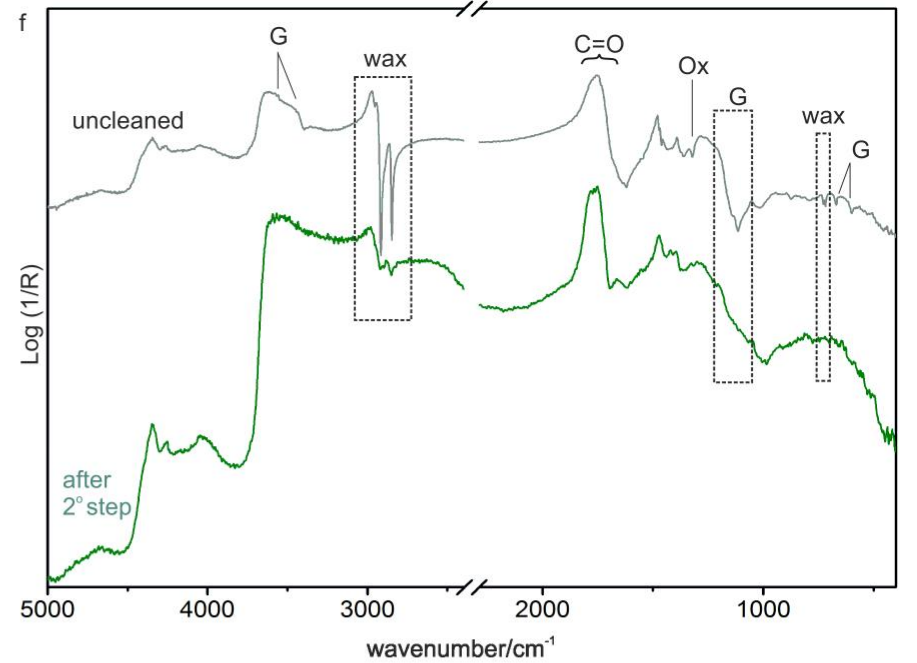

g
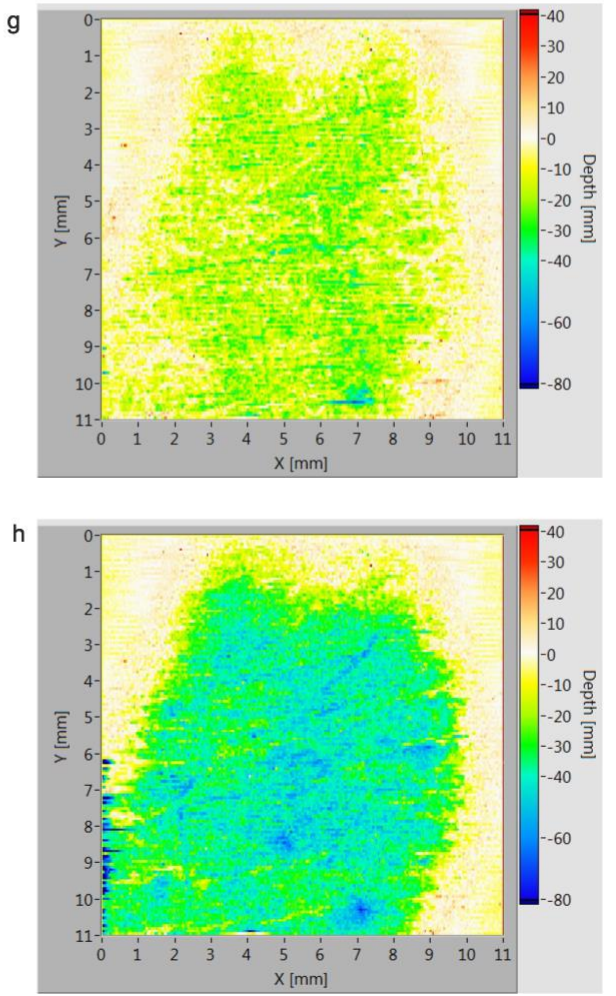

Fig. 9. Floral painting. (a) microscopic photograph of UV-induced fluorescence of a cross-section of a sample, layers removed in the cleaning test marked by a yellow arrow; OCT tomograms recorded: (b) at the sample collection spot length $=0.54 \mathrm{~mm}$; (c) before cleaning, collected at $t_{0}$, with a yellow arrow marking the layers removed in the cleaning test, length of this and following tomograms is $11 \mathrm{~mm}$; (d) after step 1, at $t_{1}$; (e) after step 2, at $t_{3}$. (f) Reflection FTIR spectra collected before cleaning (grey line) and after step 2 (green line). OCT differential maps showing deficit of material: $(\mathrm{g})$ after step 1 - calculated from subtraction of surfaces recovered at $t_{1}$ and $t_{0}$; $(h)$ after both steps calculated from subtraction of surfaces recovered at $t_{3}$ and $t_{0}$. 


\section{Discussion}

The results from the systematic study on the complementary use of OCT and reflection FTIR spectroscopy in monitoring cleaning trials of model samples and of two real paintings here presented show how OCT provided a straightforward overview of the build-up of layers in all the examined objects while chemical identification of the superficial exposed materials was properly achieved by reflection FTIR spectroscopy. Overall the results show that OCT is less effective in imaging of a set of layers covered with a partially absorbing layer (as in the case of varnishes under the overpaint in the Floral painting). Also the estimation of their thickness is hampered because of the multi-scattering phenomenon [33] in the upper paint layer. Additionally, if the varnishes have similar near IR optical properties and/or were applied over short period of time (e.g. model sample $D+A+L$ ) their interfaces may be less visible in the tomograms. It's worth to mention that historical paintings are even more suitable than model samples for OCT imaging. As a matter of fact, deterioration phenomena of old varnish layers and soot/dust deposits make the layers' boundaries better distinguishable; on the contrary, the glossiness of model samples' surfaces contribute significantly to the presence of mirror reflection artefacts. Nevertheless, the use of a high resolution OCT instrument is crucial for the examination of historical paintings where the average thickness of a single varnish layer is typically in the range of 10-20 $\mu \mathrm{m}$, since for the sake of the monitoring of removal of such layers it is important that the axial resolution is significantly higher than the layer's thickness.

Reflection FTIR spectroscopic analysis is mostly affected by the presence of spectral interferences hampering compound differentiation. This limit becomes crucial in the monitoring of the cleaning treatment as in the case of the D+A model, showing band overlapping of the varnishes, or in the case of the Floral painting where carbonyl functionalities of the oil binder and the natural varnish are not clearly discernible. For these objects OCT stratigraphic imaging adequately compensated FTIR shortfall during cleaning treatments. In the case of the sample D+M and as well as in the Floral painting, due to the specific optical, morphological, and chemical properties of the samples, FTIR analysis was able to provide chemical information also for the inner layers, assisting OCT build-up of the stratigraphy.

Generally speaking, the fine cross correlation of the OCT tomogram analysis of the sample stratigraphy with chemical characterization provided by FTIR during cleaning proved to be particularly valuable for monitoring cleaning progress in terms of observation of a thickness reduction of the outermost layer combined with chemical changes at the sample surface. Further interesting considerations rise up about the evaluation of the reached cleaning level considering the presence of residues of the removed varnish and its thickness distribution over the cleaned area. Compared to OCT, FTIR has a much higher sensitivity for identification of remains of removed layers (e.g. remains of acrylic varnish in the case of the sample D+A or beeswax residues in the sample $\mathrm{D}+\mathrm{B}$ ). On the other hand, in some cases the OCT imaging helps in assessing whether there are some remains of varnish localised within the brushstrokes or other concaves of the surface (e.g. sample $\mathrm{D}+\mathrm{M}$ ) which can help in interpretation of FTIR data, and in optimisation of the cleaning procedure.

The apparent discrepancy between OCT and FTIR results in the detection of varnish residues remarks a more general limitation in interpretation of the data from both techniques. Specifically, when in OCT tomograms one does not see a layer that was supposed to be removed and at the same time it is still detected with FTIR, it is difficult to resolve if the varnish was removed as a layer but is still remaining in the porous paint layer or in the craquelure and/or is it still present on the surface in a layer thinner than ca $2 \mu \mathrm{m}$ (below OCT's axial resolution). 


\section{Conclusions}

Reflection FTIR spectroscopy and Optical Coherence Tomography were used as complementary techniques, successfully assessing the selective cleaning of varnished easel paintings with a complex build-up of layers.

Spectral variations that emerged from FTIR were consistent with the gradual decrease of number and thickness of varnish layers visible in OCT images. FTIR gives information on the chemical composition of superficial layers; changes in the relative intensity of marker bands related to varnish, paint, and uncovered layer inform about the cleaning progress. OCT technique, especially OCT differential maps, is a useful tool to evaluate the thickness or amount of material removed and evenness of the cleaning treatment.

The fine correlation of the experimental findings by the two techniques clearly shows how a combined use helps to overcome their intrinsic limits and allows to measure chemical, optical and morphological changes of the object in course of the treatment, step by step .

Overall, the complementary application of FTIR and OCT techniques provided a valuable non-invasive tool to support in situ the conservator's evaluation of tests to remove the unwanted layers one by one and leaving the original historical layers intact.

\section{Acknowledgements}

The authors wish to thank Dr Wiesława Topolska and professor Jadwiga W. Łukaszewicz from the Institute for the Study, Conservation and Restoration of Cultural Heritage, Faculty of Fine Arts, Nicolaus Copernicus University, for lending the Bruker Alpha instrument used to study some of the models, as well as the colleagues from WP7.1a of the IPERION CH project for fruitful discussions and staff of the Rijksmuseum, Amsterdam for providing the Floral painting for the experiment.

This research has been co-financed by H2020 IPERION CH project (contract number: 654028) and conducted with the partial use of the research infrastructure of Interdisciplinary Centre for Modern Technology of Nicolaus Copernicus University in Toruń, Poland, financed by Regional Operational Programme for KujawskoPomorskie Voivodship (Project No. RPKP.05.04.00-04-001/10).

\section{References}

[1] A. Phenix, K. Sutherland, The cleaning of paintings: effects of organic solvents on oil paint films, Studies in Conservation, 2 (2001) 47-60 https://doi.org/10.1179/sic.2001.46.Supplement-1.47.

[2] A. Phenix, R. Wolbers, Removal of varnish: organic solvents as cleaning agents, in: J.H. Stoner, R. Rushfield (Eds.) The Conservation of Easel Paintings, Routledge, Abingdon, 2012, pp. 524-554.

[3] M.F. Mecklenburg, A.E. Charola, R.J. Koestler (Eds.) New Insights into the Cleaning of Paintings: Proceedings from the Cleaning 2010 International Conference, Smitsonian Institution Scholarly Press, Washington D.C., 2013.

[4] Integrated Platform for the European Research Infrastructure ON Cultural Heritage - H2O2O project: www.iperionch.eu.

[5] B. Brunetti, C. Miliani, F. Rosi, B. Doherty, L. Monico, A. Romani, A. Sgamellotti, Non-invasive Investigations of Paintings by Portable Instrumentation: The MOLAB Experience, Topics in Current Chemistry, 374 (2016) 41-75, https://doi.org/10.1007/s41061-015-0008-9.

[6] C. Miliani, F. Rosi, B.G. Brunetti, A. Sgamellotti, In Situ Noninvasive Study of Artworks: The MOLAB Multitechnique Approach, Acc. Chem. Res., 43 (2010) 728-738. 
[7] K. Kahrim, A. Daveri, P. Rocchi, G. de Cesare, L. Cartechini, C. Miliani, B.G. Brunetti, A. Sgamellotti, The application of in situ mid-FTIR fibre-optic reflectance spectroscopy and GC-MS analysis to monitor and evaluate painting cleaning, Spectrochimica Acta Part A, 74 (2009) 1182-1188, https://doi.org/10.1016/j.saa.2009.08.051.

[8] F. Rosi, L. Cartechini, L. Monico, F. Gabrieli, M. Vagnini, D. Buti, B. Doherty, C. Anselmi, B.G. Brunetti, C. Miliani, Tracking metal oxalates and carboxylates on painting surfaces by non-invasive reflection mid-FTIR spectroscopy, in: F. Casadio, K. Keune, P. Noble, A. van Loon, E. Hendriks, S. Centeno, G. Osmond (Eds.) Metal Soaps in Art - Conservation \& Research, Springer Nature (in press), 2018.

[9] B. Ormsby, E. Kampasakali, C. Miliani, T. Learner, An FTIR-Based Exploration of the Effects of Wet Cleaning Treatments on Artists' Acrylic Emulsion Paint Films, e-PRESERVATION Science, 6 (2009) 186-195.

[10] F. Rosi, L. Legan, C. Miliani, P. Ropret, Micro transflection on a metallic stick: an innovative approach of reflection infrared spectroscopy for minimally invasive investigation of painting varnishes, Analytical and Bioanalytical Chemistry, 409 (2017) 3187-3197, https://doi.org/10.1007/s00216-017-0260-7.

[11] Complete list of papers on application of OCT to examination of artwork may be found at http://www.oct4art.eu: Optical coherence tomography for examination of works of art, (accessed 20/09/2015).

[12] P. Targowski, M. Iwanicka, Optical Coherence Tomography: its role in the non-invasive structural examination and conservation of cultural heritage objects - a review, Appl. Phys. A, 106 (2012) 265-277, https://doi.org/10.1007/s00339-011-6687-3.

[13] C.S. Cheung, M. Spring, H. Liang, Ultra-high resolution Fourier domain optical coherence tomography for old master paintings, Opt. Express, 23 (2015) 10145-10157, https://doi.org/10.1364/OE.23.010145.

[14] P. Targowski, M. Iwanicka, B.J. Rouba, C. Frosinini, OCT for Examination of Artwork, in: W. Drexler, G. Fujimoto (Eds.) Optical Coherence Tomography. Technology and Applications, Springer, Cham Heidelberg New York Dordrecht London, 2015, pp. 2473-2495, available on line at: http://link.springer.com/referencework/10.1007/978-3-319-06419-2/page/5.

[15] M. Iwanicka, D. Kończalska, P. Targowski, B.J. Rouba, Non-Contact and Non-Invasive Monitoring of Overpaint Removal with Optical Coherence Tomography, in: M.F. Mecklenburg, A.E. Charola, R.J. Koestler (Eds.) New Insights into the Cleaning of Paintings: Proceedings from the Cleaning 2010 International Conference, Smitsonian Institution Scholarly Press, Washington D.C., 2013, pp. 27-29.

[16] M. Iwanicka, P. Targowski, E.A. Kwiatkowska, M. Sylwestrzak, Application of optical coherence tomography (OCT) for monitoring of some conservation treatments, in: D. Saunders, M. Strlič, C. Korenberg, N. Luxford, K. Birkhölzer (Eds.) Lasers in the Conservation of Artworks IX. Proceedings of the International Conference on Lasers in the Conservation of Artworks (Lacona IX), 7-10 September 2011, London, UK, Archetype Publications Ltd, London, 2013, pp. 11-25.

[17] M. Góra, P. Targowski, A. Kowalczyk, J. Marczak, A. Rycyk, Fast spectral optical coherence tomography for monitoring of varnish ablation process, in: M. Castilleo, P. Moreno, M. Oujja, R. Radvan, J. Ruiz (Eds.) Lasers in the Conservation of Artworks. Proceedings of the International Conference Lacona VII, Madrid, Spain, 17-21 September 2007, CRC Press,Taylor \& Francis Group, London, 2008, pp. 23-27.

[18] P. Targowski, J. Marczak, E.A. Kwiatkowska, M. Sylwestrzak, A. Sarzyński, Optical coherence tomography for high resolution real-time varnish ablation monitoring, in: D. Saunders, M. Strlič, C. Korenberg, N. Luxford, K. Birkhölzer (Eds.) Lasers in the Conservation of Artworks IX. Proceedings of the International Conference on Lasers in the Conservation of Artworks (Lacona IX), 7-10 September 2011, London, UK, Archetype Publications Ltd, London, 2013, pp. 26-31.

[19] J. Striova, B. Salvadori, R. Fontana, A. Sansonetti, M. Barucci, E. Pampaloni, E. Marconi, L. Pezzati, M.P. Colombini, Optical and spectroscopic tools for evaluating Er:YAG laser removal of shellac varnish, Studies in Conservation, 60 (2015) S91-S96, https://doi.org/10.1179/0039363015Z.000000000213. 
[20] J. Striova, R. Fontana, M. Barucci, A. Felici, E. Marconi, E. Pampaloni, M. Raffaelli, C. Riminesi, Optical devices provide unprecedented insights into the laser cleaning of calcium oxalate layers, Microchemical Journal, 124 (2016) 331-337, https://doi.org/10.1016/j.microc.2015.09.005.

[21] P. Targowski, M. Iwanicka, L. Tymińska-Widmer, M. Sylwestrzak, E.A. Kwiatkowska, Structural Examination of Easel Paintings with Optical Coherence Tomography, Acc. Chem. Res., 46 (2010) 826-836, https://doi.org/10.1021/ar900195d.

[22] M. Iwanicka, G. Lanterna, C.G. Lalli, F. Innocenti, M. Sylwestrzak, P. Targowski, On the application of Optical Coherence Tomography as a complimentary tool in an analysis of the 13th century Byzantine Bessarion Reliquary, Microchemical Journal, 125 (2016) 75-84, https://doi.org/10.1016/j.microc.2015.11.014.

[23] M. Iwanicka, J. Musiela, J.W. Łukaszewicz, H. Stoksik, M. Sylwestrzak, The potential of OCT for assessing laser assisted removal of deposits from ceramic tiles, in: P. Targowski, M. Walczak, P. Pouli (Eds.) Lasers in the Conservation of Artworks XI, Proceedings of the International Conference LACONA XI, Kraków, Poland, 20-23 September 2016, NCU Press, Torun, 2017, https://doi.org/10.12775/3875-4.07.

[24] C. Miliani, F. Rosi, A. Daveri, B.G. Brunetti, Reflection infrared spectroscopy for the non-invasive in situ study of artists' pigments, Appl. Phys. A, 106 (2012) 295-307, https://doi.org/10.1007/s00339-011-6708-2.

[25] F. Rosi, A. Daveri, P. Moretti, B.G. Brunetti, C. Miliani, Interpretation of mid and near-infrared reflection properties of synthetic polymer paints for the non-invasive assessment of binding media in twentiethcentury pictorial artworks, Microchemical Journal, 124 (2016) 898-908, https://doi.org/10.1016/j.microc.2015.08.019.

[26] S. Vahur, A. Teearu, I. Leito, ATR-FT-IR spectroscopy in the region of 550-230cm-1 for identification of inorganic pigments, Spectrochimica Acta Part A: Molecular and Biomolecular Spectroscopy, 75 (2010) 10611072, https://doi.org/10.1016/j.saa.2009.12.056.

[27] M. Maia, A.I.R.N.A. Barros, F.M. Nunes, A novel, direct, reagent-free method for the detection of beeswax adulteration by single-reflection attenuated total reflectance mid-infrared spectroscopy, Talanta, 107 (2013) 74-80, https://doi.org/10.1016/j.talanta.2012.09.052.

[28] G. Socrates, Infrared and Raman Characteristic Group Frequencies: Tables and Charts, 3rd Edition, John Wiley and Sons, Chichester, 2004.

[29] L. Brambilla, C. Riedo, C. Baraldi, A. Nevin, M.C. Gamberini, C. D’Andrea, O. Chiantore, S. Goidanich, L. Toniolo, Characterization of fresh and aged natural ingredients used in historical ointments by molecular spectroscopic techniques: IR, Raman and fluorescence, Analytical and Bioanalytical Chemistry, 401 (2011) 1827-1837, https://doi.org/10.1007/s00216-011-5168-z.

[30] L. Monico, F. Rosi, C. Miliani, A. Daveri, B.G. Brunetti, Non-invasive identification of metal-oxalate complexes on polychrome artwork surfaces by reflection mid-infrared spectroscopy, Spectrochimica Acta Part A: Molecular and Biomolecular Spectroscopy, 116 (2013) 270-280, https://doi.org/10.1016/j.saa.2013.06.084.

[31] F. Casadio, K. Keune, P. Noble, A. van Loon, E. Hendriks, S. Centeno, G. Osmond (Eds.) Metal Soaps in Art - Conservation \& Research, Springer Nature (in press), 2018.

[32] F. Rosi, A. Daveri, B. Doherty, S. Nazzareni, B.G. Brunetti, A. Sgamellotti, C. Miliani, On the Use of Overtone and Combination Bands for the Analysis of the CaSO4-H2O System by Mid-Infrared Reflection Spectroscopy, Appl.Spectroscopy, 64 (2010) 956-963, https://doi.org/10.1366/000370210792080975.

[33] H. Liang, B. Peric, M. Spring, D. Saunders, M. Hughes, A.G. Podoleanu, Non-invasive imaging of subsurface paint layers with optical coherence tomography, in: J. Townsend, L. Toniolo, F. Cappitelli (Eds.) Conservation Science 2007, Non-Destructive Testing, Milan, Italy, 10-11 May 2007, Archetype Publications, Milan, 2007, pp. 171-176. 